\title{
Estudios sociolingüísticos y prácticas comunitarias para la documentación activa y el reencuentro con las lenguas indígenas del Ecuador ${ }^{1-2}$
}

Marleen Haboud ${ }^{3}$

Pontificia Universidad Católica del Ecuador ORCID ID: 0000-0002-6966-6375

Recibido: 26 de enero de 2019 Aceptado: 3 de marzo de 2019

\section{Resumen}

Este artículo se enmarca en el Programa de investigación interdisciplinaria Oralidad Modernidad que se desarrolla con, desde y para comunidades de hablantes de lenguas minorizadas, y que tiene como objetivo primordial la documentación activa y el refuerzo de las lenguas indígenas del Ecuador de hoy. Luego de una breve contextualización sobre la problemática de las lenguas minorizadas en el mundo, hacemos referencia a la situación de las lenguas indígenas en el Ecuador, para luego

\section{Abstract}

Framed within the community-based Oralidad Modernidad Research Program, which is carried out with minoritized languages in Ecuador; this article first describes some of the difficulties minority languages face in the world, as well as the situation of indigenous languages in Ecuador. Secondly, it underlines some concepts regarding documentation and revitalization processes, language maintenance and loss. Finally, it describes two of the various projects developed by Oralidad Modernidad giving

1 Sociolinguistic studies and community practices for active linguistic documentation and the re-encountering with the indigenous languages of Ecuador 2 Elementos contenidos en este artículo pueden encontrarse en varios informes que sobre Oralidad Modernidad reposan en los archivos del Programa, así como en varias de las fuentes bibliográficas que aquí se incluyen, como Haboud 2018, Haboud 2010, Haboud \& Limerick 2017, Haboud 2014, y Mayorga \& Haboud 2013. 3 Ph.D en Lingüística, por la Universidad de Oregon. Actualmente se desempeña como Docente-Investigadora en la Pontificia Universidad Católica del Ecuador. Correo: maboud@puce.edu.ec 
puntualizar algunos conceptos importantes para este trabajo. Finalmente, se describen tres de los proyectos que ha desarrollado Oralidad Modernidad, su metodología, productos, logros y dificultades.

Palabras clave: Ecuador, investigación interdisciplinaria, lenguas indígenas, documentación activa, revitalización, metodología descolonizadora, procesos de investigación dentro-fuera-dentro special attention to their goals, methodology, products, and long-term achievements.
Keywords: Ecuador, Interdisciplinary research, Indigenous Ecuadorian Languages, Active documentation, Revitalization, Decolonizing methodology, Inside-out-inside research processes

\section{Introducción}

Investigaciones desarrolladas durante los últimos años en relación con la vitalidad de las lenguas (UNESCO 2010, UNICEF 2009) demuestran que más del $50 \%$ del alrededor de 6.500 lenguas que se estima existen en el mundo, corren el riesgo de desaparecer en el curso de unas pocas generaciones. En relación con los países latinoamericanos, la mayoría tiene una población indígena que va del $3 \%$ al $10 \%$ del total de su población. Los censos oficiales elaborados entre 2000 y 2008 indican que el total de población indígena identificada en América Latina corresponde a algo más del 6\% (30 millones) de la población que habita en Latinoamérica (479.824.248). En esta región existen alrededor de 420 lenguas distintas, de las cuales 103 $(24,5 \%)$ son lenguas transfronterizas utilizadas en dos o más países (Sichra, 2009). El quechua (quichua, Kichwa) es hablado en siete países de América del Sur: Argentina, Bolivia, Brasil, Colombia, Chile, Ecuador y Perú. Las lenguas indígenas se encuentran en un severo peligro de desaparición. Según varios estudiosos, del total de población indígena americana en países en los que se habla español, solo el $15 \%$ es monolingüe en su lengua, el $35 \%$ es monolingüe en castellano, y el $50 \%$ es bilingüe (lengua indígena-castellano). Desgraciadamente, no se trata de un bilingüismo balanceado, sino de uno que denomino minorizado, pues, dada la situación de subordinación de los hablantes, la lengua con menos prestigio tiende al desplazamiento.

Las trece lenguas indígenas del Ecuador no son una excepción, pues, en algún grado, están todas amenazadas. Estas lenguas, identificadas también como minorizadas por su condición de desigualdad en la 
sociedad (Caláforra, s/f), necesitan entrar en procesos de revitalización y, por tanto, ser usadas en todos los contextos sociocomunicativos. Como bien sabemos, con la desaparición de una lengua se pierden conocimientos ancestrales únicos ${ }^{4}$. Así, enmarcado en trabajos interdisciplinarios con, desde y para comunidades de base, este artículo se propone compartir algunos de los procesos de documentación activa-revitalización desarrollados por el Programa Oralidad Modernidad en algunas comunidades indígenas del Ecuador con el fin de documentarlas activamente y por tanto apuntar a su revitalización. En relación con los proyectos, describiremos tres de ellos: (a) GeolingüísticaEcuador, tanto con el componente de georeferenciación, como con el uso de mapas parlantes, (b) Así Dicen Mis Abuelos (ADMA), y (c) Voces Andinas y Conocimientos Ancestrales. Mencionaremos, a lo largo de este escrito, sus objetivos, metodología, resultados y logros.

\section{El Ecuador y su diversidad}

Con una extensión de $283.561 \mathrm{~km} 2$, Ecuador es un país con gran riqueza en cuanto a la geodiversidad, etnodiversidad y diversidad lingüística. Con una población de casi 17 millones de habitantes (proyección censal a 2018), se reconocen al momento 14 Nacionalidades $^{5}$ indígenas y 13 lenguas indígenas todavía vitales (Mapa 1). Todas ellas se encuentran en algún grado de peligro. Es importante notar que los datos demográficos en relación con los pueblos indígenas discrepan considerablemente: así, mientras el último censo muestra que el 7\% de la población es indígena, según la Confederación Nacional de Indígenas del Ecuador la cifra ascendería hasta un $40 \%{ }^{6}$. Los datos sobre las lenguas difieren aún más y, excepto por algunas investigaciones recientes, son pocos los estudios que puntualizan su uso y vitalidad (ver Haboud 2013 y 2018; King y Haboud 2002 y 2012; Narváez 2014; www.oralidadmodernidad.com).

Recordemos que, desde el periodo precolombino, las lenguas ancestrales han estado en contacto entre ellas mismas y, a partir de la conquista española (1500), en un contacto intenso y prolongado con el castellano. En los últimos años, además, se ha incrementado el

4 http://www.unesco.org/new/en/culture/themes/endangered-languages.

5 Acogiéndonos a la preferencia de la población indígena, que todo aquello que los denomina se escriba con mayúsculas, en este trabajo se ha optado por escribir con mayúsculas los nombres de sus lenguas y pueblos, así como el término Nacionalidad(es).

6 http://www.acnur.org/biblioteca/pdf/7015.pdf?view=1 
contacto con lenguas extranjeras como el inglés. Adicionalmente, el Ecuador, y sobre todo su población indígena, ha enfrentado una serie de situaciones que han vulnerado las lenguas y culturas ancestrales, como, por ejemplo, inestabilidad política y económica desde la década de los 70, lo cual llevó al país a enfrentar una inflación anual de hasta $80 \%$ entre 1995 y el año 2000. A pesar de la dolarización de la economía en el año 2000, y aunque han bajado las tasas de inflación del país a menos del $2 \%$, sabemos que las poblaciones más vulnerables son las indígenas ${ }^{7}$. Fenómenos naturales como terremotos e inundaciones han afectado a la población en el Ecuador, especialmente a las poblaciones indígenas. Por otra parte, la presencia de empresas transnacionales, grupos guerrilleros y la militarización de las fronteras, han afectado profundamente a poblaciones indígenas, especialmente en pueblos transfronterizos. Todo esto ha agudizado procesos de migración interna y externa que tienden a acelerar el desplazamiento de la lengua y la cultura, pues la modernidad y la globalización promueven la castellanización y el bilingüismo minori-

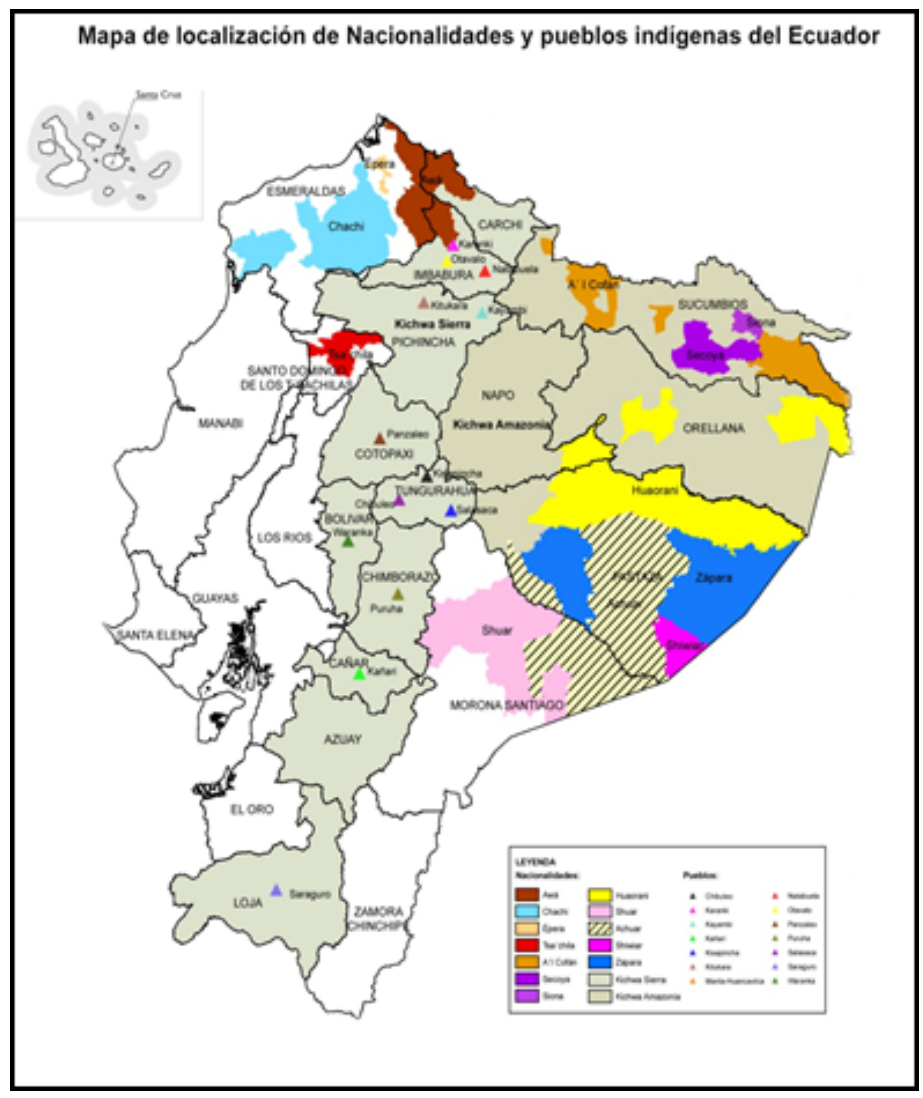

Mapa 1. Nacionalidades y lenguas del Ecuador

7 https://contenido.bce.fin.ec/resumen_ticker.php?ticker_value=inflacion 
zado para dar paso a un multilingüismo de prestigio que excluye las lenguas ancestralmente subordinadas (King \& Haboud, 2012).

\section{3. ¿Cómo medir la vulnerabilidad de una lengua?}

Como bien sabemos, no es fácil medir la vitalidad de una lengua pues es necesario obtener datos cuantitativos y cualitativos sobre el uso real (e imaginado) de las lenguas en diversos contextos comunicativos y su relación con el contexto sociohistórico de los hablantes. Con frecuencia sabemos que una lengua ha desaparecido cuando es demasiado tarde. UNESCO $(2009,2010)$, con el fin de facilitar la sistematización de datos, ha diseñado escalas de vitalidad ${ }^{8}$ que se enfocan en aspectos claves de la vitalidad de una lengua, como es la transmisión intergeneracional. Estas escalas, si bien sabemos que son inexactas y que no pueden ser tomadas como plantillas rígidas, nos ayudan a determinar si una lengua se encuentra saludable, si está debilitada, en estado de coma, o cercana a la muerte. El siguiente diagrama muestra la escala de vitalidad en relación con la transmisión intergeneracional:

Tabla 1. Escalas sugeridas de transmisión intergeneracional de la lengua

\begin{tabular}{ccl}
\hline $\begin{array}{c}\text { Grado de } \\
\text { vitalidad }\end{array}$ & Grado & \multicolumn{1}{c}{ Población de hablantes } \\
\hline $\begin{array}{c}\text { No corre } \\
\text { peligro }\end{array}$ & 5 & $\begin{array}{l}\text { Todas las generaciones hablan la lengua. Además no } \\
\text { se ha interrumpido la transmisión de la misma entre } \\
\text { generaciones. }\end{array}$ \\
\hline Vulnerable & 4 & $\begin{array}{l}\text { La lengua es utilizada por algunos niños en todos los } \\
\text { ámbitos, y por todos los niños en ámbitos restringidos. }\end{array}$ \\
\hline $\begin{array}{c}\text { Claramente en } \\
\text { peligro }\end{array}$ & 3 & $\begin{array}{l}\text { Los niños ya no aprenden la lengua como lengua ma- } \\
\text { terna. La lengua es utilizada por la generación paren- } \\
\text { tal para arriba. }\end{array}$ \\
\hline $\begin{array}{c}\text { Seriamente en } \\
\text { peligro }\end{array}$ & 2 & $\begin{array}{l}\text { Sólo la generación de los abuelos habla la lengua. La } \\
\text { generación de los padres a veces todavía entiende la } \\
\text { lengua pero no la utiliza para dirigirse a sus hijos. }\end{array}$ \\
\hline $\begin{array}{c}\text { En situación } \\
\text { crítica }\end{array}$ & 1 & $\begin{array}{l}\text { Los ancianos sólo recuerdan parte de su lengua y no } \\
\text { la utilizan de modo permanente, ya que sólo quedan } \\
\text { pocas personas con las que hablar en ella. }\end{array}$ \\
\hline Extinta & 0 & \begin{tabular}{l} 
Ya no queda nadie que pueda hablar ni recordar la lengua. \\
\hline
\end{tabular} \\
\hline
\end{tabular}

Fuente: A partir de UNESCO 2009, 2010

8 De los nueve factores que propone UNESCO, seis evalúan la vitalidad de una lengua, dos analizan las actitudes hacia una lengua y uno evalúa la necesidad de realizar procesos de documentación. 
Para determinar la vitalidad de una lengua hay que tomar en cuenta varios otros factores como el número absoluto de hablantes de una lengua, la proporción de hablantes en relación con la población en general, los contextos de uso de las lenguas, los nuevos ámbitos de comunicación, su uso en el ámbito de la educación formal, su posicionamiento oficial dentro de la legislación nacional y, por supuesto, la actitud de los hablantes en relación con su lengua. Sin embargo, por razones de espacio, consideraremos aquí solo la transmisión intergeneracional.

\section{Breve puntualización de conceptos}

Oralidad Modernidad ${ }^{9}$ y sus proyectos desarrollan actividades de documentación activa, esto es, una documentación que se basa en el trabajo desde, con y para las comunidades de hablantes con el propósito de llegar, no solo a obtener productos concretos y culturalmente pertinentes, sino más bien a logros que permitan a los hablantes buscar por cuenta propia mejores días para sus lenguas y su cultura. Para esto, buscamos realizar permanentemente intercambios más justos, compartiendo conocimientos, habilidades, problemas y buscando soluciones desde las realidades propias de los hablantes. Es que 'intercambiar' es más que dar y recibir. Es crear conciencia y compromiso, lo que nos lleva a cambiar en mucho las reglas y las prácticas tradicionalmente seguidas en la investigación ${ }^{10}$, de modo que los generalmente investigados pasan a ser investigadores.

Desde esta perspectiva, la documentación activa debe incidir en la autodeterminación de los hablantes y provocar procesos de revitalización. Se prevé, entonces, que los procesos de documentación y revitalización van de la mano y que los hablantes son parte de cada uno de estos procesos, desde sus inicios. En cuanto a las estrategias de los procesos, partimos, no desde arriba-abajo (top-down) o de abajo-arriba (bottom-up), sino del centro mismo de las comunidades, para volver a ellas (adentro-afuera-adentro), tratando, al mismo tiempo, de impactar en la sociedad en general. Nada de esto es posible si no nos ajustamos a la ética de la investigación que se basa en el diálogo, la transparencia, el respeto y la equidad garantizando los derechos de los participantes. Pasos, cada uno de estos, que tratamos de seguir permanentemente.

9 www.oralidadmodernidad.com

10 En relación con el concepto de intercambio justo en el área de las Ciencias Sociales, ver Haboud y Limerick, 2017 y www.pachaysana.org 


\section{Programa de investigación interdisciplinaria Oralidad Mo- dernidad y tres de sus proyectos}

Oralidad Modernidad se propuso, desde su inicio, determinar la situación de vitalidad de las lenguas ancestrales del Ecuador y entender las estrategias desarrolladas por los hablantes, consciente o inconscientemente, con el fin de mantener y revitalizar sus lenguas y culturas. Por supuesto, concebimos la(s) lengua(s) como ente(s) dinámico(s) e íntimamente relacionado(s) con cambios sociales, identitarios y de posicionamiento social. Algunas de las preguntas que han guiado este programa son: ¿Cómo lidian los hablantes de lenguas de tradición oral con la modernidad? ¿Cómo se enfrentan a cambios rápidos y abruptos, producto de la sociedad globalizante? ¿Cómo han afectado las migraciones masivas, no solo a quienes se van, sino también a quienes se quedan, no solamente en términos lingüístico-culturales, sino también en la creación de culturas transnacionales imaginadas? ${ }^{11}$ ¿Cómo pueden las nuevas tecnologías favorecer el mantenimiento de las lenguas, y no su pérdida?

En la búsqueda de respuestas, Oralidad Modernidad ha venido trabajando con 12 de las 13 lenguas indígenas del país: Kichwa de la Sierra, la Amazonía y Galápagos, Awap'it, Cha'palaa, Tsa'fiki y Sia Pedee, en la costa, y A'ingae, Achuar, Shuar, Shiwiar, Baikoka, Paikoka y Waotededo en la región amazónica (Ver Mapa 1). Se ha realizado una amplia recopilación de videograbaciones que, en colaboración con las comunidades, están siendo transcritas, traducidas y analizadas, y que son, al mismo tiempo, el punto de partida para la elaboración de materiales que propenden al refuerzo lingüístico y cultural. Hemos producido, además, fichas informativas sobre cada una de las lenguas, DVD y CD testimoniales, cuentos infantiles impresos y en animación digital, así como artículos académicos, que son entregados a las comunidades. Paralelamente, y como parte del compromiso permanente del proyecto, se han impartido talleres de iniciación en el uso de software lingüístico, uso de nuevas tecnologías y producción de materiales videograbados. Por medio de encuentros académicos nacionales e internacionales, se comparte y evalúa permanentemente cada una de las actividades realizadas, dando cabida a profesionales y académicos del mundo entero ${ }^{12}$ en una constante reflexión sobre el dinamismo de las lenguas, los efectos del contacto, las expectativas de los hablantes y las realidades múltiples desde las que se viven las lenguas e identidades en conflicto.

11 Ver King y Haboud 2012.

12 Algunas de estas actividades pueden verse en www.oralidadmodernidad.com y en Haboud \& Ostler 2013. 
Se trabaja en la consolidación de un archivo digital de las lenguas indígenas y de variedades de español ecuatoriano registradas hasta el momento con el fin de dar cuenta de la realidad social, geolingüística y geoambiental de las lenguas, de las diferentes formas de comunicación, características dialectales y especificidades de cada lengua y variedad. Se trabaja también en crear una base de documentación sólida que esté a buen recaudo y, al mismo tiempo, al alcance de los hablantes e interesados en trabajar en el refuerzo de las lenguas. Uno de los proyectos más extensos desarrollados por Oralidad Modernidad ha sido el estudio sociolingüístico georeferenciado de la vitalidad lingüística de las lenguas del Ecuador, el mismo que se desarrolló con el proyecto GeolingüísticaEcuador, que describimos a continuación.

\subsection{Proyecto 1 - GeolingüísticaEcuador}

A partir de datos cuanti-cualitativos georeferenciados sobre el (des)uso de las lenguas indígenas del país conjuntamente con hablantes bilingües de las distintas Nacionalidades del país, GeolingüísticaEcuador se ocupa de determinar la situación de vitalidad de las lenguas en relación con los territorios y los contextos sociocomunicativos de uso de las lenguas, y de representarlas cartográficamente. En este proyecto se discute y analiza la situación de la(s) lengua(s) en relación con la localización de los hablantes, lo que nos lleva a repensar conceptos como territorio, territorialidad, (des)territorialization. Se determina, además, el conocimiento que los hablantes tienen de una lengua, sus actitudes, preferencias y prácticas lingüísticas, las tendencias de transmisión intergeneracional, desplazamiento y/o pérdida de las lenguas, así como las expectativas lingüísticas de los hablantes y sus propuestas y acciones para propiciar el mantenimiento.

Además de diseñar mapas que representan las Nacionalidades y lenguas indígenas del país en relación con los territorios oficialmente asignados a cada Nacionalidad, en este proyecto se desarrollan mapas temáticos y mapas comparativos que nos permiten ver la localización de las comunidades, tanto a nivel nacional como local, la interrelación de las distintas comunidades, y por tanto de las lenguas.

A partir de 6.700 entrevistas sociolingüísticas georeferenciadas desarrolladas con 12 de las 13 lenguas indígenas vitales del país, nos ha sido posible conocer más de cerca las tendencias de uso y desuso de las lenguas y representarlas cartográficamente acercándonos de 
forma más precisa a la situación de la vitalidad lingüística del país ${ }^{13}$. A manera de ilustración, la siguiente sección muestra, de forma breve, el estudio realizado con la Nacionalidad Tsa'chila.

\subsubsection{La Nacionalidad Tsa'chila y su lengua el Tsa'fiki}

El Tsa'fiki (lengua verdadera), lengua hablada por la Nacionalidad Tsa'chila (gente verdadera), pertenece a la familia lingüística Barbacoana sur y está localizada en la provincia de Santo Domingo de los Tsa'chilas, a 200 kilómetros de la capital del Ecuador, Quito. Según el último censo (2010), su población era de 2.640 habitantes distribuidos en ocho comunidades: Cóngoma Grande (Santo Juan), Los Naranjos, El Búho de los Colorados, El Poste, Peripa, Chigüilpe, Otongo Mapalí y la comunidad Filomena Aguavil (Tahuaza) en donde la lengua originaria, Tsa'fiki, se ha perdido; de ahí que este estudio no haya tomado en cuenta la última comunidad. Las comunas reúnen a familias nucleares con vínculos de consanguinidad y afinidad patrilineales y se constituyen en núcleos de cooperación y de ayuda mutua. El siguiente mapa de identificación de la Nacionalidad Tsa'chila nos muestra la ubicación de dicha Nacionalidad, así como las tendencias de desplazamiento de sus miembros. Tómese en cuenta que cada punto corresponde a una persona que se autoreconoce como Tsa'chila, pero que no se corresponde al $100 \%$ con cada hablante de Tsa'fiki.

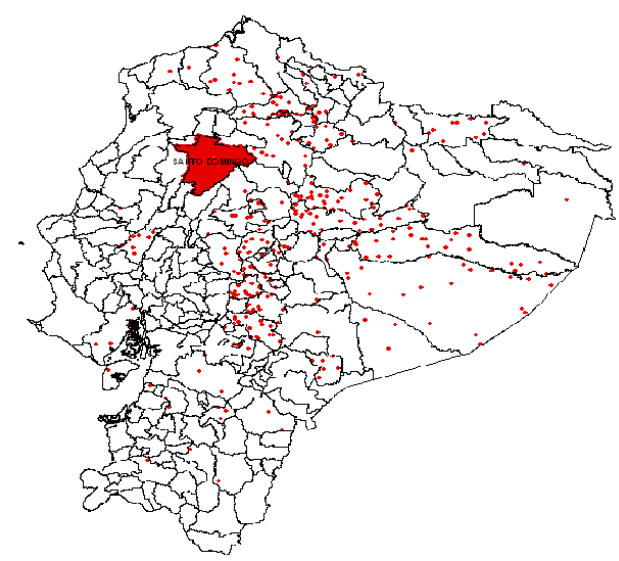

Mapa 2. Mapa de autoidentificaciónde la Nacionalidad Tsa'chila ${ }^{14}$

13 Para un detalle sobre los procedimientos seguidos por GeolinguisticaEcuador, ver Mayorga \& Haboud 2013, Haboud 2010-2014 y Haboud 2018.

14 A menos que se indique expresamente, todos los mapas que aquí se presentan han sido diseñados por Oralidad Modernidad y el subproyecto GeolingüísticaEcuador. Para citar, ver Haboud, 2010-2014. 


\section{Metodología del estudio}

El presente estudio se realizó con una muestra de 187 personas de las siete comunidades mencionadas y cuya edad estaba en el rango 17 a 80 años. La muestra fue escogida según el número de habitantes de cada localidad ${ }^{15}$. Con el total de la población muestreada, se realizaron conversaciones libres, entrevistas sociolingüísticas, testimonios y talleres de arte. Todas las entrevistas fueron georeferenciadas con el fin de determinar la localización exacta de los entrevistados y de posibilitar el posterior mapeo. La entrevista que consta de 95 preguntas, 90 cerradas y 5 abiertas, se desarrolló en la lengua preferida por los entrevistados, aunque siempre se la inició en Tsa'fiki. En este trabajo, hacemos únicamente mención a las preguntas relacionadas con el conocimiento de la lengua, su uso, y la transmisión intergeneracional. Es importante recalcar que este instrumento fue usado como una entrevista oral por parte del equipo conformado por miembros de la Nacionalidad (hablantes bilingües Tsa'fiki-castellano), y de la universidad, estudiantes de lingüística y de geografía, quienes fueron capacitados en técnicas de georreferenciación, así como también en la importancia de las lenguas y culturas ancestrales.

Una vez recogidos los datos, estos fueron digitados en una plantilla de Excel y analizados con el uso del programa SPSS. Se procedió entonces a representar cartográficamente algunos de los resultados, sobre todo aquellos relacionados con el conocimiento y uso de la lengua. La primera representación, sin embargo, fue la de las comunidades estudiadas en la que se visibiliza la ubicación de cada comunidad y sus vías de acceso, la cercanía a centros urbanos y carreteras principales, elementos importantes en el mantenimiento o pérdida de una lengua.

Los siguientes mapas son representativos de las siete comunidades estudiadas y de la distribución de la muestra del estudio:

15 La entrevista utilizada es una versión actualizada de la entrevista utilizada por Haboud en su estudio de 1994. Algunos de los alcances se realizaron con miembros de comunidades tsa'chila, miembros del equipo GeolingüísticaEcuador, y con Jorge Gómez, con quien colaboramos en este trabajo. Mis agradecimientos a Fernando Ortega quien, conjuntamente con miembros de las comunidades, trabajó con los cálculos de la muestra del estudio, y posteriormente con el análisis estadístico. Detalles de todos los pasos seguidos en este estudio, puede verse en Haboud, 2010-2014. 


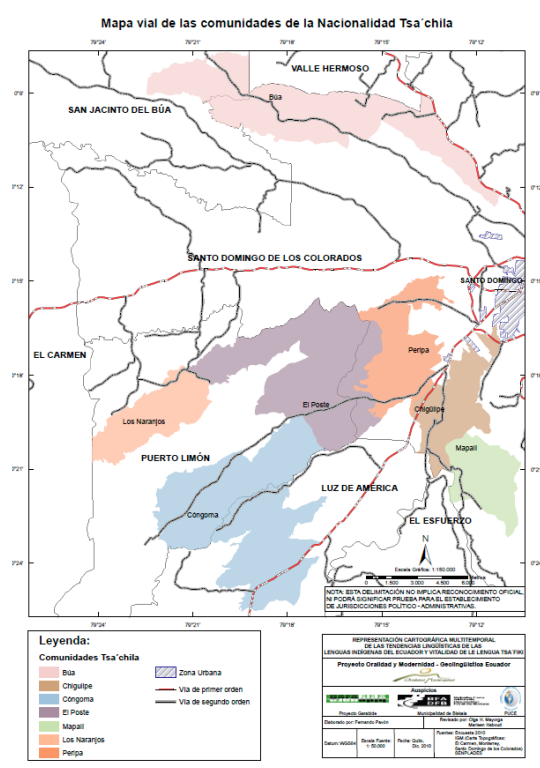

Mapa 3. Mapa vial y comunidades

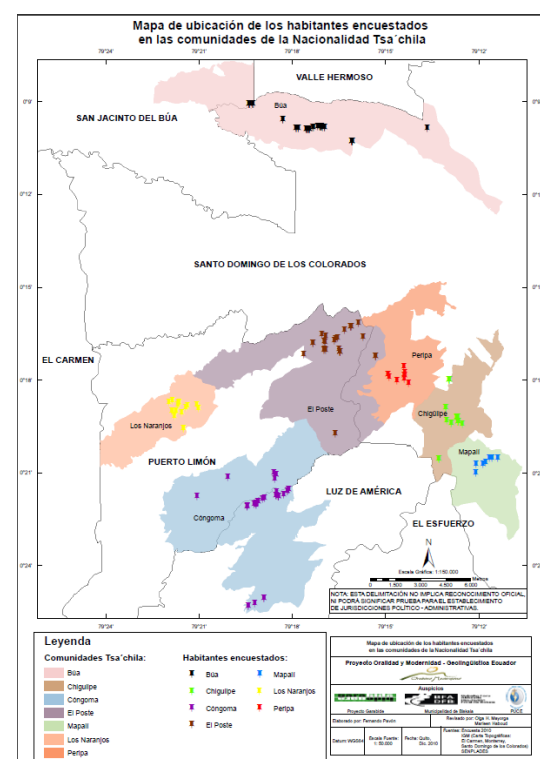

Mapa 4. Distribución de la muestra del estudio

\section{Algunos resultados}

\section{Conocimiento y uso de la lengua}

Como puede verse en la tabla siguiente (Tabla 2), el 77.7\% de los entrevistados respondió que su lengua materna es el Tsa'fiki y el 20.7\% dijo ser bilingüe de nacimiento. Estos resultados deberían favorecer el uso de la lengua ancestral; sin embargo, no es esa la percepción de los hablantes en cuanto al uso por parte de las distintas generaciones.

Tabla 2. Lengua materna de los entrevistados

\begin{tabular}{ccc}
\hline Lengua & $\mathbf{n =}$ & $\mathbf{\%}$ \\
\hline Tsa'fiki & 143 & 77.7 \\
\hline $\begin{array}{c}\text { Tsa'fiki y } \\
\text { castellano }\end{array}$ & 38 & 20.7 \\
\hline Castellano & 2 & 1.1 \\
\hline Total & 184 & 100 \\
\hline
\end{tabular}




\section{Percepción del uso de las lenguas intergeneracionalmente}

A decir del 98.4\% de los entrevistados, la lengua mayoritariamente utilizada por sus abuelos es (o era) el Tsa'fiki, y un porcentaje similar (92.4\%) comentó que era también la lengua más usada por los padres; sin embargo, solo un $4.3 \%$ de los entrevistados dijo que los jóvenes generalmente hablan Tsa'fiki, pues al momento la tendencia generalizada es al bilingüismo y la castellanización. Nótese que un $59.2 \%$ de los entrevistados comentó que los jóvenes prefieren hablar únicamente el castellano. Si bien esta es la percepción de los entrevistados, trabajos realizados a partir de etnografías lingüísticas llevadas a cabo entre el año 2014 y el 2017, muestran que, al menos en dos comunidades de las siete, los jóvenes ya no usan la lengua ancestral (Ver Carpenter, s/f.).

Tabla 3. Percepción del uso de las lenguas según generaciones (\%)

\begin{tabular}{cccc}
\cline { 2 - 4 } & Abuelos & Padres & Jóvenes \\
\hline Tsa'fiki & 98.4 & 92.4 & 4.3 \\
\hline $\begin{array}{c}\text { Tsa'fiki y } \\
\text { castellano }\end{array}$ & .5 & 1.1 & 59.2 \\
\hline Ambas & 1.1 & 6.5 & 36.4 \\
\hline
\end{tabular}

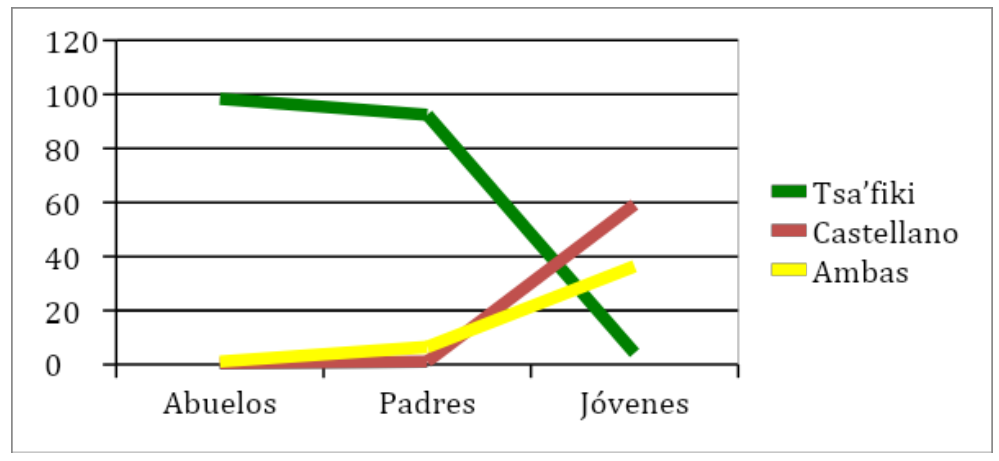

Gráfico 3. Percepción del uso de las lenguas según generaciones (\%) 
Los siguientes mapas $(5,6$ y 7$)$ muestran comparativamente la percepción que tienen los entrevistados en cuanto a una alta tendencia al desplazamiento por parte de los jóvenes. Si tomamos en cuenta que el color verde representa la lengua Tsa'fiki, el amarillo el uso bilingüe (Tsa'fiki-castellano), y el rojo, el castellano, y analizamos los mapas con una mirada horizontal, vemos que solamente en una de las comunidades se mantiene el Tsa'fiki, mientras que, en los seis restantes, predominan el uso bilingüe y el uso del castellano.

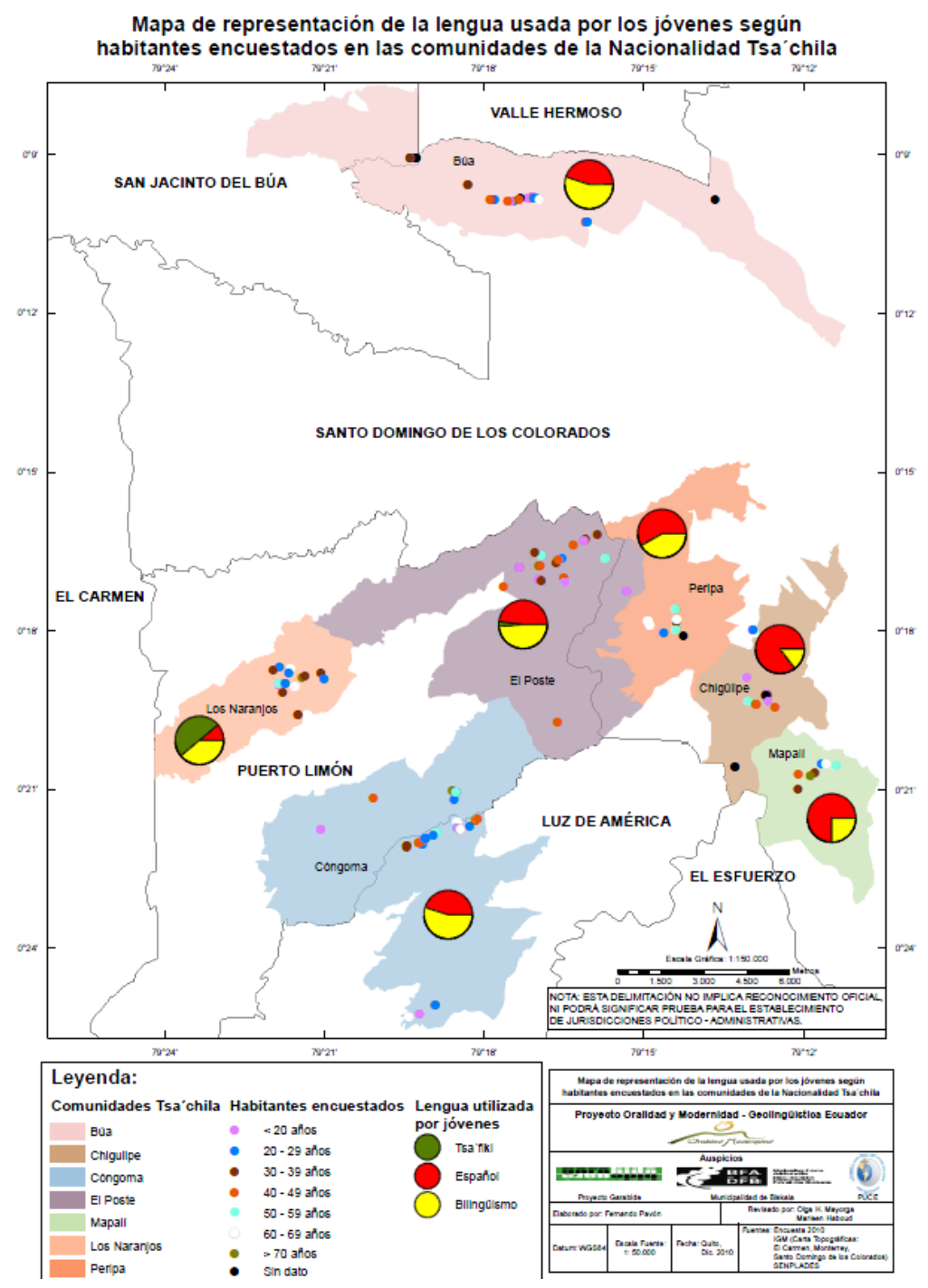

Mapa 5. Lenguas habladas por abuelos 


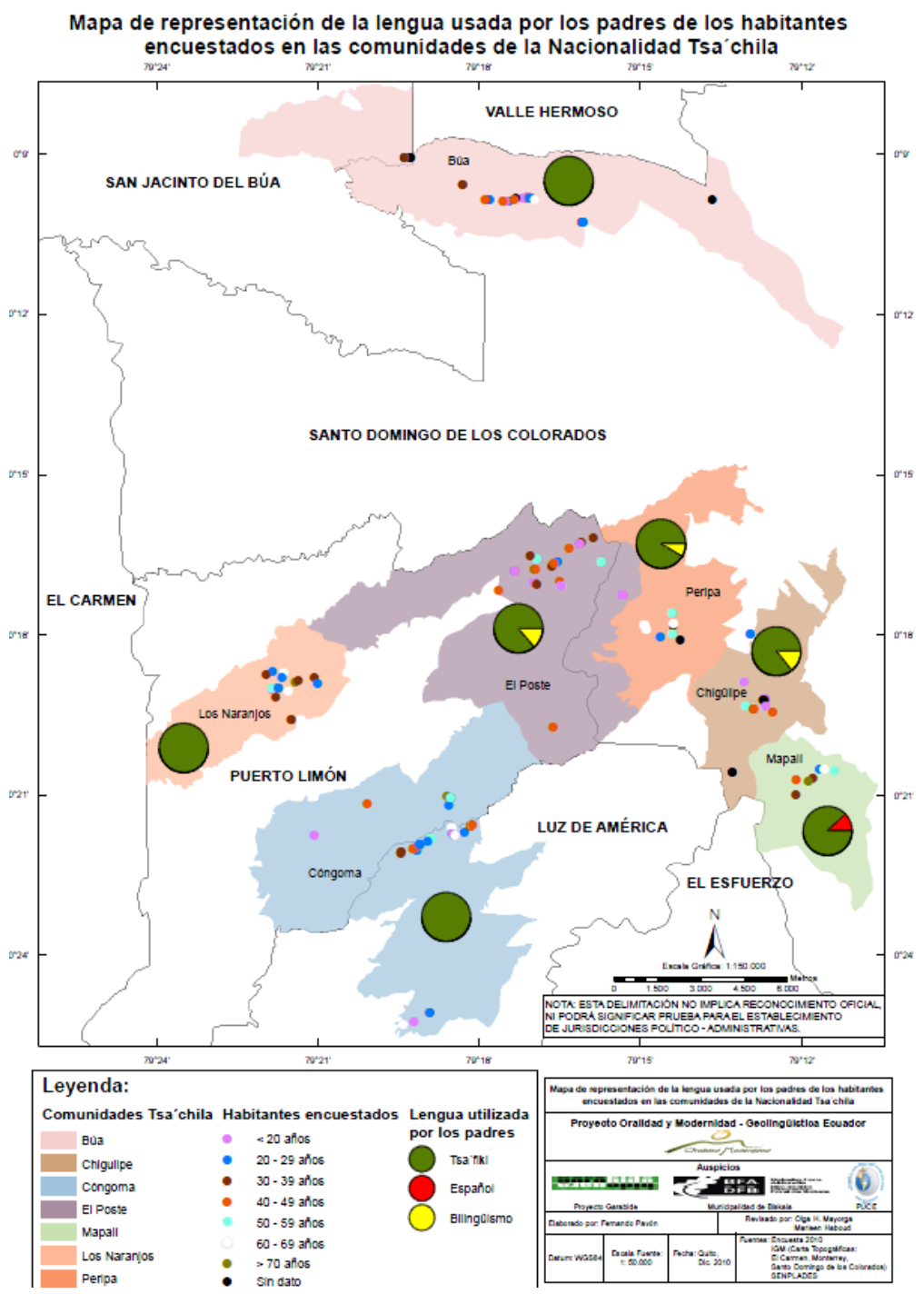

Mapa 6. Lenguas habladas por padres 


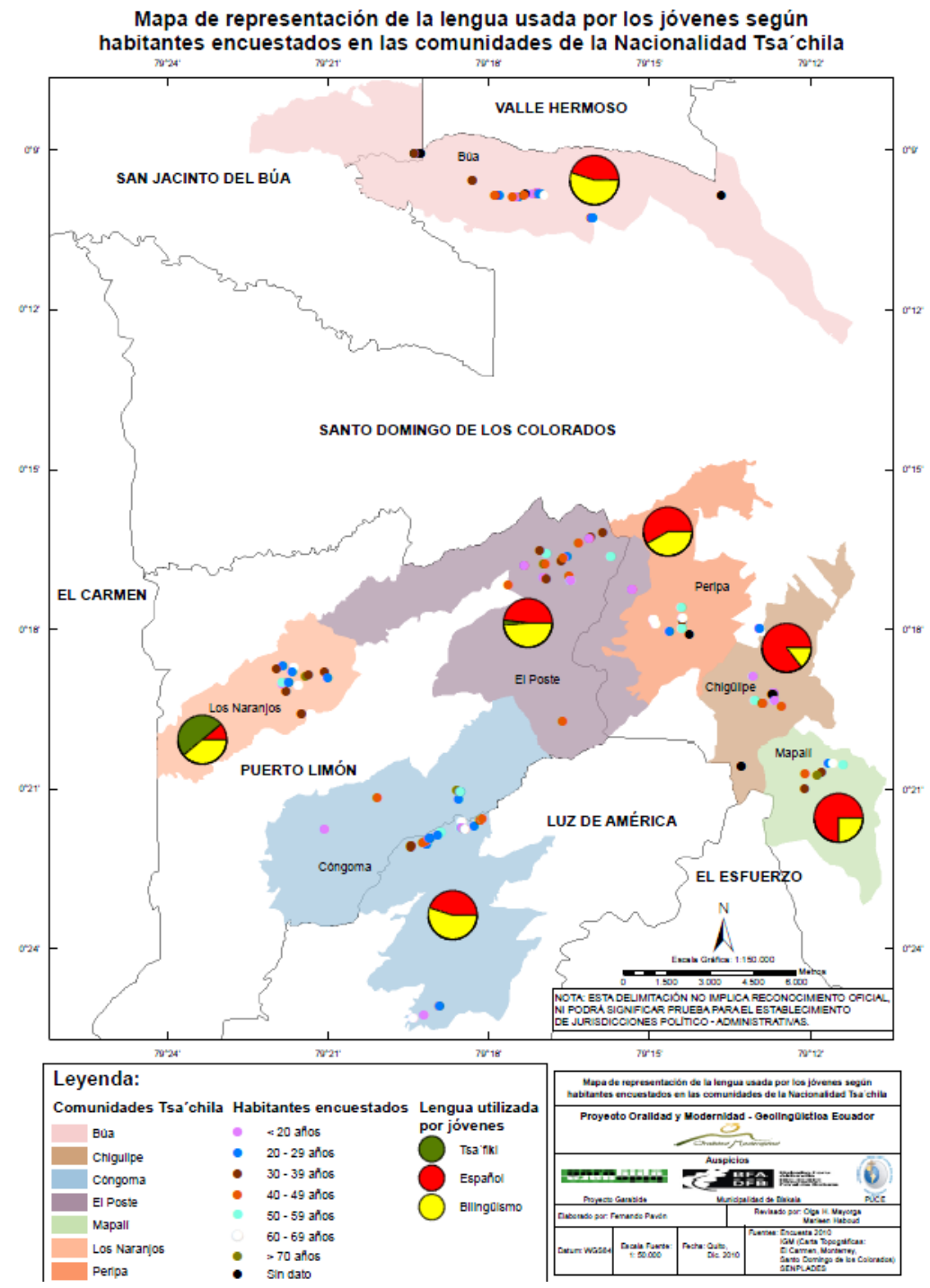

Mapa 7. Lenguas habladas por jóvenes 
Tales porcentajes coinciden con algunos de los comentarios de los entrevistados, quienes afirman: "Antes no [la gente] sabían hablar castellano, solo unas dos que tres palabras, sabían [...] Mis papás, solo Tsa'fiki hablaban, ellos no hablaban castellano [...] ahora, los dos; algunos ya no saben Tsa'fiki" ${ }^{16}$.

Muchos de los habitantes con los que hemos dialogado en las comunidades, temen que se dé una irrecuperable pérdida de la lengua: “[...] porque los jóvenes solo hablan en castellano con los ancianos [...] Yo me preocupo mucho de cómo nosotros podemos vivir cuando llegue la muerte $[. . .]^{\prime 17}$.

Tal preocupación resulta, probablemente, del hecho de que solo el 59\% de los entrevistados afirmó hablar Tsa'fiki con sus hijos y un porcentaje aún mayor indicó que, aunque ellos hablan en Tsa'fiki, los hijos responden en castellano y mezclan las lenguas. Estos comentarios han ido en aumento durante las visitas realizadas a las comunidades en los dos últimos años (2016-2017).

En relación con otros factores importantes para la vitalidad de la lengua, vemos que en general, el Tsa'fiki no se escribe, ya sea porque los entrevistados nunca aprendieron a escribir en su lengua, ya sea porque les parece demasiado difícil. No se trata, sin embargo, de falta de interés por parte de la población por escribir su lengua, sino más bien de desconocimiento de cómo hacerlo. Durante talleres de arte realizados en la comunidad de El Poste, algunos estudiantes escribieron espontáneamente el cuento que estaban ilustrando y luego lo leyeron. Esto nos muestra cómo una pequeña motivación redunda positivamente en el uso de la lengua.

En cuanto a los nuevos contextos de comunicación como las nuevas tecnologías, que son factores importantes para determinar la vitalidad de la lengua, son prácticamente inexistentes en Tsa'fiki. En cuanto al factor documentación de la lengua (importantísimo en el mantenimiento de la vitalidad), los habitantes comentan que sí hay documentación en la que ellos mismos han colaborado, sin embargo, poco es lo que ha llegado a los hablantes para poder usarlo a su favor; de ahí que insistamos en la necesidad de desarrollar documentación activa.

16 Entrevista con JA en Tsa'fiki. Traducción de Jhonny Calazacón (Nov, 2011).

17 Entrevista con GA en Tsa'fiki. Traducción de Jhonny Calazacón (Nov, 2011). 
Uno de los últimos factores que menciona UNESCO como importante para mantener la lengua, se refiere a las actitudes lingüísticas tanto por parte de los hablantes, como de las instancias oficiales. Puede verse en carteles públicos, por ejemplo, en los Ministerios de Cultura y Centros de Arte, que aparecen imágenes de miembros de las comunidades Tsa'chilas en algunas propagandas; sin embargo, esto impacta poco -o nada- en el uso de la lengua, y tiende más bien a la folklorización de la cultura.

El camino recorrido y construido por los pueblos indígenas del Ecuador en las últimas décadas parecía haberlos llevado a conseguir importantes conquistas en el campo educativo, político, social, económico, lingüístico y cultural; desgraciadamente, estas conquistas no han sido suficientes para mantener, reforzar o desarrollar sus lenguas y su cultura. Así, vemos que la lengua Tsa'fiki está también en peligro y que necesitará nutrirse en todos los ámbitos.

Es muy importante subrayar que, si bien los resultados en relación con la vitalidad de la lengua son más bien negativos, quienes participaron directamente en el estudio aquí mencionado han continuado liderando cambios, ya sea desde instancias políticas, ya sea desde sus propias comunidades ${ }^{18}$.

\subsubsection{Cuando la georreferenciación no es una opción: mapas parlantes...}

En el caso de Nacionalidades y comunidades que rechazaron el mapeo basado en la georreferenciación, trabajamos con mapas parlantes. Este fue, por ejemplo, el caso de la Nacionalidad Awa, hablantes de la lengua Awapit (lengua barbacoana), y originarios de Colombia, que habitan ahora en tres provincias ecuatorianas, dos de la Sierra y una de la Costa. Ilustramos aquí el caso de una de las comunidades, Pambilar ${ }^{19}$. En este caso, el sitio de trabajo fue la escuela de la comunidad donde se reunieron varios de los habitantes del lugar y se organizaron

18 Un trabajo similar al de la Nacionalidad Tsa'chila se ha completado con 12 de las 13 lenguas vivas del Ecuador. Los informes respectivos están siendo validados con las comunidades, y se discute al momento sobre formas idóneas de publicación. 19 Gracias a Leonardo Auz (Geógrafo) y Antonio Salazar (Comunicador, miembro de Oralidad Modernidad), quienes realizaron el trabajo de campo de este estudio preliminar. Igualmente a Olga Mayorga, entonces miembro de Oralidad Modernidad, con quien trabajamos conjuntamente en las primeras etapas de los sondeos sociolingüísticos georeferenciados. Para un trabajo anterior sobre el tema, ver https:// www.academia.edu/25710101/Vitalidad_de_la_lengua_awapit_a_partir_de_un_estudio_preliminar_ 
en cuatro grupos. Cada uno de ellos representó sus comunidades con mucha especificación con amplios dibujos que luego fueron expuestos $y$, posteriormente, georeferenciados y entregados a la comunidad conjuntamente con materiales de audio y video recogidos durante esa primera visita.

El uso de los mapas parlantes constituye una metodología abierta y flexible que permite la expresión libre de los miembros de la comunidad, y que unida a la tecnología actual, permite visualizar y entender un territorio a partir de un dibujo, de una línea o de un punto en los que se conjugan las percepciones, vivencias y saberes de la comunidad. Esto, combinado con el análisis de las entrevistas sociolingüísticas, permitió, no solo establecer la ubicación de la comunidad, sino también entender mejor su organización, intereses, expectativas y temores, y aprender, además, sobre la vulnerabilidad de la lengua que, a pesar de algunos esfuerzos desplegados por los hablantes para su mantenimiento, va disminuyendo en los contextos de uso. Una de las fuentes importantes de refuerzo de la lengua, es la radio local que intenta transmitir en Awapit, y que lamentablemente carece de programas radiales en su propia lengua. Los mapas parlantes, como comentamos, son muy útiles, no solo para visualizar gráficamente la comunidad, sino también para fortalecer su identidad. Así, estos mapas, como su nombre lo indica, dejan de ser instrumentos técnicos para convertirse en interacción social.

\subsection{Proyecto 2 - Así Dicen Mis Abuelos (ADMA) ${ }^{20}$}

Desde y con comunidades rurales, y por medio de talleres de arte, organizados en comunidades rurales, tanto comunidades indígenas como no-indígenas, ADMA busca recordar, compartir y difundir los saberes ancestrales del Ecuador con el fin de incidir, por una parte, en el autorefuerzo identitario, la agentividad y el empoderamiento de los hablantes, y, por otra, en el conocimiento y el respeto por el otro. Nuestro trabajo consiste en visitar distintos rincones del país en busca de adultos mayores ${ }^{21}$ que recuerden y compartan con jóvenes y niños sus saberes. A partir de estos relatos desarrollamos ac-

20 Gracias a Mayfe Ortega, Directora de este proyecto, por la elaboración parcial de este informe. Para mayor detalle de las actividades y productos de ADMA, ver www. mayfeortega.com

21 En algunas de las comunidades visitadas, como las de la Nacionalidad Waorani, estos talleres fueron liderados por jóvenes de entre 15 y 18 años, y tuvieron una muy alta participación de personas de todas las edades quienes decidieron, no solo representar sus propias historias, sino también actuarlas. 
tividades artísticas y lúdicas para que las nuevas generaciones puedan apropiarse de estos, sus saberes. ADMA procesa el trabajo de los talleres generando productos lúdicos y multilingües que por medio de un festival anual se devuelven a cada una de las comunidades participantes.

Los talleres se inician con narraciones de tradición oral local que, luego de haber sido recreadas artísticamente por miembros de la comunidad, se convierten en el punto de partida para la creación de materiales impresos y audiovisuales tendientes a perennizar las voces, creatividad e imaginarios de los participantes, y a reforzar sus destrezas lingüísticas, su cultura y su identidad.

Este proyecto promueve prácticas de interculturalidad en su vinculación permanente con la comunidad. Al igual que los proyectos ya descritos, su quehacer está permanentemente guiado por los principios de la ética de la investigación y el compromiso en la búsqueda de que las voces que han sido silenciadas por siglos "salgan de su escondite". En este sentido, ADMA busca disminuir actitudes discriminatorias y racistas que por falta de conocimiento del otro dificultan las relaciones sociales y la comunicación. La posibilidad de que los hablantes nativos accedan a tecnología de punta, es un paso importante que puede generar actitudes positivas de sí mismos, el análisis de su propia lengua y la búsqueda de prácticas educativas que respeten, en la práctica, la diversidad de las lenguas minorizadas y de sus hablantes.

En relación con los festivales interculturales organizados por ADMA, estos se inician con muestras itinerantes, en las que después de recorrer cada localidad donde ya se ha realizado un taller de arte, así como escuelas y centros culturales, se muestran los procesos y productos desarrollados durante los talleres; esto con el fin de que la mayor cantidad de niños y jóvenes puedan disfrutar y aprender jugando. Durante los festivales, representantes de todas las comunidades participantes se desplazan a otras localidades con el fin de visitar, conocer, compartir algo de su cultura. Como bien dice su directora, Mayfe Ortega, "[...] no podemos dejar de creer en la importancia de promover un despertar intercultural en los niños de un Ecuador diverso [...], para ello tratamos de volver reales, conceptos magnos como plurinacionalidad e interculturalidad generando experiencias vivenciales enriquecidas por el intercambio".

Hasta el momento, ADMA ha producido dos series de cuentos y juegos multilingües (2010 y 2011) en las provincias de Santo Domingo de 
los Tsa'chilas (lengua Tsa'fiki), Napo (lengua Kichwa), Pastaza (lengua Waotededo), Cotopaxi (lengua Kichwa), Pichincha, Manabí y Esmeraldas (castellano de la Sierra y de la Costa) ${ }^{22}$. En el año 2011, se incluyó en este trabajo la lengua de señas y, a partir de ello, se produjo el Primer Festival Internacional de Cine Sordo (www.festivalcinesordo.com) y el Encuentro internacional Voces e Imágenes que Unen ${ }^{23}$.

\subsection{Proyecto 3 - Voces Andinas y Conocimientos Ancestrales}

Este proyecto se inició en el 2017 con comunidades kichwa de la Sierra norte y centro del país, y continúa al momento en zonas semiurbanas, donde se ha perdido la lengua Kichwa, pero se mantiene el conocimiento ancestral. Voces Andinas tiene como fin "re-encontrarnos, por medio de narrativas, con los conocimientos ancestrales relacionados con salud, enfermedad, formas de curación, especialmente, con el uso de plantas medicinales". Trabaja para ello, con equipos interdisciplinarios, multilingües y multiculturales capacitados en el uso del software lingüístico libre Lexique-pro, con el que ha sido posible sistematizar el conocimiento que, sobre plantas medicinales, comparten las conocedoras (mamas) y los conocederos (taytas) de las comunidades. Quienes recogen los datos, son jóvenes de equipos locales que han recibido capacitación en el uso de estas nuevas tecnologías (Ver Foto 1).

Recordemos que la narración de historias, como forma de documentación, proporciona un espacio donde surgen voces que comparten informalmente los recuerdos, conocimientos, prácticas y expectativas de los hablantes. Puesto que las narraciones tienen lugar en un entorno propio y se dan con miembros de sus propias comunidades, los narradores se sienten libres de compartir sus experiencias. Esto ha abierto espacios para que los más jóvenes, que son quienes desarrollan el proyecto, aprendan de sus padres, parientes, abuelos, con quienes poco han conversado.

Así, un ambiente familiar y estas nuevas tecnologías, permiten compartir, ofrecer relatos, testimonios, historias, y mostrar, no solo cómo se puede usar cada planta, sus beneficios y restricciones, sino recordar la historia, pensar en sí mismos y en su vida, levantando sus voces, de modo que quienes han dejado de oírlos, vuelvan a interesarse y escuchar.

22 Se puede acceder al material producido por ADMA en www.mayfeortega.com

23 Festival cine sordo y Voces e imágenes que unen (PUCE 2012) 


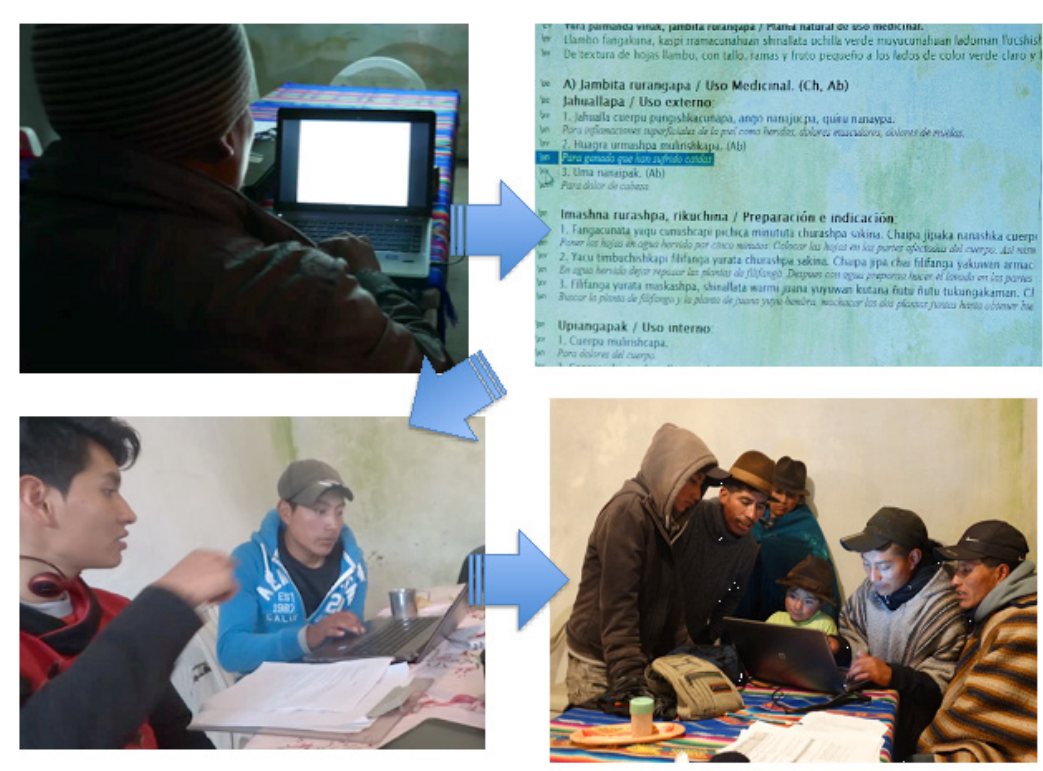

Foto 1. Talleres de capacitación del software Lexiquepro

Luego de casi 20 meses de trabajo en cuatro comunidades, hemos recopilado más de 180 plantas de uso medicinal con su morfología, usos, restricciones y bondades. Según el deseo de las comunidades, todo el material se presenta tanto en la lengua ancestral como en castellano, y está enriquecido con videos narrativos y centenares de fotos. Los procesos seguidos y la naturaleza de estos productos convierten los léxicos en etnografías de la vida de las comunidades llenas de conocimientos, no solo sobre las plantas, sino también sobre las estrategias de siembra, cosecha, cuidado y uso de cada planta, y sobre historias de enfermedades y curaciones, de tristezas y alegrías que se reviven en su propia lengua y que están estrechamente ligadas a la cosmovisión y la cultura de cada hablante.

Desde el punto de vista de la etnobotánica, ha sido posible identificar taxonomías propias relacionadas con principios dicotómicos como frío y calor, masculino y femenino, negro y blanco, etc., y determinar las partes específicas de cada planta en donde se concentra su efecto curativo.

Voces andinas y conocimientos ancestrales nos ha demostrado, desde adentro, desde la comunidad, que el reencuentro con el conocimiento propio, las relaciones interculturales, la adopción de nuevas tecnologías de documentación y revitalización, promueven, no solo la reapropiación y la difusión de los saberes, sino también la emergen- 
cia de nuevos activistas de la lengua. Así, se avanza de forma espontánea, y prácticamente inevitable, de procesos de documentación a procesos de revitalización ${ }^{24}$.

\section{A modo de reflexión: la interdisciplinariedad y metodología de Oralidad Modernidad y sus proyectos}

Aunque con especificidades, los proyectos desarrollados por/con Oralidad Modernidad se caracterizan por ser interdisciplinarios, co-participativos, basados en la ética de la investigación, el respeto $\mathrm{y}$ el compromiso con las comunidades. Mantenemos un trabajo con, desde y para los hablantes en un esfuerzo que apunta hacia la documentación activa y, por tanto, al desarrollo de iniciativas de revitalización.

En cuanto a la metodología, si bien es rigurosa, es también flexible y se ajusta a las múltiples situaciones de las comunidades a las que históricamente hemos dejado de escuchar. Los talleres de capacitación multilingües y multiculturales aseguran, más que la fiabilidad de los datos, avanzar hacia el autoreconocimiento, el empoderamiento y la agentividad. Como dice Mama Virgina (junio, 2018): "Hemos llegado hasta aquí por nuestros esfuerzos, nuestro conocimiento, nuestras habilidades, que creemos que no tenemos. Ojalá nuestro conocimiento ayude a runas y mishus ${ }^{25}$ a encontrar lo que es sumak kawsay ...."

Lejos de llegar a una conclusión, queremos recordar (y recordarnos) que hay todavía mucho por hacer, que el desplazamiento de las lenguas va de la mano con situaciones de inequidad y sus efectos sociales y políticos. Si bien estas situaciones son globales, las soluciones deben ser particulares y específicas para cada caso y cada historia, y deben construirse con la coparticipación, el respeto y la ética.

\section{Bibliografía}

Calaforra G. (s/f). Lengua y poder en las situaciones de minorización lingüística. Recuperado de http://www.uv.es/calaforr/CursColonia.pdf

24 En www.oralidadmodernidad.com, pueden verse algunos de los procesos y productos de Voces Andinas y Conocimientos Ancestrales.

25 Términos kichwas que corresponden a: runa 'persona', mishu 'mestizo', sumak kawsay 'vida de calidad' 
Guevara, D. (1972). El Castellano y el Quichua en el Ecuador. Quito: Casa de la Cultura Ecuatoriana.

Haboud, M. (2018). Documentación activa con, desde y para los hablantes de lenguas amenazadas. En K. Störl. T. Valiente y E. Gugenberger (Eds.), La reciprocidad entre lengua y cultura en las sociedades andinas - Estudios de romanística, lingüística y antropología americana (pp.37-50). Berlín: Peter Lang GMBH.

Haboud, M (Ed.). (2013). Voces imágenes de las lenguas en peligro. Quito: Abya-Yala.

Haboud, M. (2011). Oralidad Modernidad. Ética, documentación activa e investigación interdisciplinaria. Quito: PUCE (ms).

Haboud, M. (2010-2014). Informe del Estudio sociolingüístico georeferenciado de la vitalidad de la lengua Tsa'fiki. Quito:PUCE (ms).

Haboud, M. (2009). Oralidad Modernidad. Informe 2009. La vitalidad de la lengua Kichwa en Cañar. Quito: PUCE (ms).

Haboud M. (2003). Vitalidad Lingüística del Quichua Ecuatoriano. (Segunda Edición). Quito: CEDAI.

Haboud, M \& Limerick, N. (2017). Language Policy and Education in the Andes. En T. McCarthy, \& S. May (Eds.), Encyclopedia of Language and Education. (3rd ed.). Springer, Cham (pp. 435-447). Recuperado de https://link.springer.com/referenceworkentry/10.1007\%2F978-3-319-02344-1_32.

Haboud, M; Howard, R.; Cru, J. \& Freeland J. (2016). Linguistic human rights and language revitalization in Latin America and the Carribean. En S. Coronel-Molina \& T. L. McCarty (Eds.), The Handbook of Indigenous Language Revitalization in the Americas (pp. 201-224). New York: Routledge.

Haboud, M. (2014). Vulnerabilidad lingüística en Ecuador: la lengua awapit. En II Coloquio Internacional de Estudios Latinoamericanos de Olomouc (CIELO2): Lengua y Política en América Latina: Perspectivas Actuales (pp. 119-147). Olomouc: Palacký University, República Checa.

Haboud, M. \& King, K. (2007). Ecuadorian Indigenous language and 
education policy and practice: Recent challenges and advances. En R.B. Baldauf \& R.B. Kaplan (Eds.), Language planning and policy in Latin America, Vol. 1: Ecuador, Mexico and Paraguay (pp. 105-114). Clevedon, UK: Multilingual Matters.

Haboud, M. \& Mayorga, O. (2011). GeolingüísticaEcuador: vitalidad de la lengua Tsa'fiki Proyecto Oralidad Modernidad 2011. Fundación Garabide, Municipalidad de Biskaia, PUCE (Quito) (ms).

King, K. \& Haboud, M. (2012). International Migration and Quichua Language Shift in the Ecuadorian Andes. En T.I. McCarty. (Ed.), Ethnography and Language Policy (pp. 139-160). New York: Routledge.

King, K. \& Haboud, M. (2002), Language planning and policy in Ecuador. En R. Kaplan,. \& R. B. Baldauf (Eds.), Current Issues in Language Planning, 3(4), 359-424. Multilingual matters.

Mayorga, O. \& Haboud, M. (2013). En M Haboud . y N. Ostler. (Eds.), Voces imágenes de las lenguas en peligro (pp. 37-50). Quito: Abya-Yala.

Narváez, D. (2014). Estudio sociolingüístico georreferenciado de la lengua Kichwa de las parroquias la Esperanza y Antonio Ante, provincia de Imbabura. Tesis para obtener el título de Licenciada en Lingüística aplicada. Quito: PUCE (sin publicar).

Sichra, I. (2009). Atlas sociolingüístico de los pueblos de América Latina. Quito: Ed. Mariscal.

UNESCO. (2009). World Atlas of Endangered Languages. Paris: UNESCO.

UNESCO. (2010). Atlas mundial de las lenguas en peligro. Paris: UNESCO. 